\title{
Cooperative Effects between Arginine and Glutamic Acid in the Amino Acid-Catalyzed Aldol Reaction
}

\author{
Guillem Valero, ${ }^{[\mathrm{a}]}$ and Albert Moyano*[a]
}

\begin{abstract}
Catalysis of the aldol reaction between cyclohexanone and 4-nitrobenzaldehyde by mixtures of L-Arg and of L-Glu in wet DMSO takes place with higher enantioselectivity (up to a seven-fold enhancement in the antialdol for the 1:1 mixture) than that observed when either L-Glu or L-Arg alone are used as the catalysts.
\end{abstract}

These results can be explained by the formation of a catalytically active hydrogen-bonded complex between both amino acids, and demonstrate the possibility of positive cooperative effects in catalysis by two different $\alpha$-amino acids.

Keywords: Amino acids, Arginine, Chirality amplification, Glutamic acid, Organocatalysis, Supramolecular catalysis

\section{Introduction}

The asymmetric aldol addition reaction is not only one of the most useful tools for the formation of carbon-carbon bonds in the stereocontrolled synthesis of chiral organic compounds, but also plays a key role in metabolic pathways. ${ }^{1}$ Aldolase enzymes (or catalytic antibodies) are able to exert an exquisite control of the regio- and the stereoselectivity of the direct aldol reaction, ${ }^{2,3}$ and much effort has been devoted to the development of purely chemical catalytic asymmetric versions of this fundamental process $^{1,4-7}$ Arguably the most important recent achievement in this area was the pioneering finding by List, Barbas III and coworkers, in $2000,{ }^{8-10}$ of the ability of proline to catalyze the direct intermolecular aldol reaction of acetone with aromatic and aliphatic aldehydes in high yields and with up to more than $99 \%$ ee. Since then, the asymmetric organic catalysis of the aldol reaction has become an actively pursued area of research., ${ }^{5,6,11-16}$ In contrast with proline, acyclic amino acids were initially considered to be poor catalysts for intermolecular enantioselective aldol reactions, since in the conditions used for the proline-catalyzed reactions (pure DMSO as a solvent at r.t.), less than $10 \%$ yields of aldol adducts were obtained. ${ }^{9}$ However, in 2005 both Amedjkoun ${ }^{17}$ and the Córdova group ${ }^{18,19}$ reported independently that, in aqueous DMSO, several unmodified acyclic amino acids (especially L-valine and L-alanine) were able to catalyze the direct catalytic asymmetric intermolecular aldol reaction with good yields and enantioselectivities. Also in 2005, Tsogoeva disclosed the use of L-histidine-based dipeptides (in dry DMSO) as catalysts for the aldol reaction. ${ }^{20}$ Subsequent work by other groups has shown that the reaction medium is crucial in determining the catalytic efficiency of acyclic amino acids in aldol reactions. A systematic study of the twenty proteinogenic amino acids in the aldol reaction between cyclohexanone and 4-nitrobenzaldehyde in DMSO and in aqueous DMSO was performed by Hayashi and co-workers. A positive water effect on the diastereoselectivity was observed for most amino acids, while the enantioselectivity was increased only when proline, serine or histidine were used. ${ }^{21}$ In pure water tryptophan appears to be the best catalyst, ${ }^{22}$ although in the presence of 2,4-dinitrophenol isoleucine was the most effective one. ${ }^{23}$ Interestingly enough, both in aqueous micelles ${ }^{24}$ and in ionic liquids ${ }^{25}$ arginine showed a high catalytic efficiency, even if in the first case the enantiomeric excesses of the aldol products were rather low.

The complete enantiomeric homogeneity of the chiral building blocks of proteins and nucleic acids (i.e., L-amino acids and Dcarbohydrates) is generally recognized as a necessary requirement for the origin of life on earth. ${ }^{26-29}$ The delivery of functionalized organic compounds by carbonaceous chondrites to the early Earth has been considered as an important source of prebiotic compounds necessary for the emergence of life. ${ }^{30}$ In this context, the discovery both of extraterrestrial amino acids in carbonaceous meteorites displaying variable excesses of the L-forms ${ }^{31-33}$ and of their ability to catalyze the enantioselective formation of D-carbohydrates from aldol reactions of glycolaldehyde in aqueos media (a reaction that significantly cannot be catalyzed by proline), ${ }^{34}$ has further increased the interest on primary amino-acid catalyzed aldol reactions. It has to be born in mind, however, that in prebiotically relevant conditions formation of carbohydrates must have taken place in the presence of complex mixtures of primary amino acids. In effect, more than 80 different amino acids have been identified in the parent bodies of the Murchison and Murray meteorites, ${ }^{31,33}$ and a recent analysis of the distribution and enantiomeric composition of three fragments of the Tagish Lake carbonaceous chondrite has also revealed the presence of several proteinogenic and nonproteinogenic acyclic amino acids of extraterrestrial origin (in some cases with $43-59 \%$ ee of the L-form). ${ }^{35}$ However, probably because of the numerous experimental and theoretical results that support the presence of a single catalyst molecule in the transition state of the rate-determining step of amino acid-catalyzed aldol reactions, ${ }^{36}$ no attention has been paid to the possibility of cooperative effects in this type of catalysis.

Among proteinogenic amino acids, arginine (Arg) occupies a very special position. Thanks to the presence of a guanidinium moeity, Arg is the most basic proteinogenic amino acid, either in aqueous solution or in the gas phase. ${ }^{37}$ As a result of that, the zwitterionic form of Arg is relatively more stable than that of other amino acids. ${ }^{38,39}$ Also due to the charged guanidinium ion, Arg participates in a variety of specific noncovalent interactions involving ionized functional groups that are observed crystal structures. Crystalline Arg itself is different from all other $\alpha$-amino 
acids: typically, $\alpha$-amino acids in the solid state arrange themselves in a peptide-like fashion with the $\alpha$-amino and the carboxylic acid groups aligned, with the side chains protruding on alternating sides; in contrast, Arg stacks end to end, enabling the guanidinium and carboxylate interaction shown in Figure $1 .{ }^{40}$

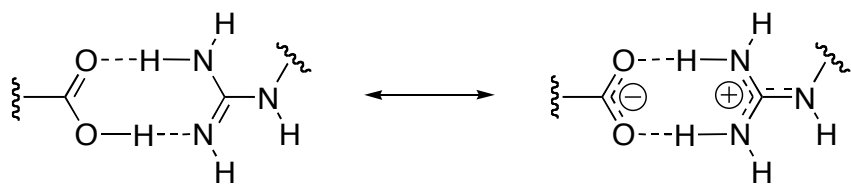

FIGURE 1 Guanidinium-carboxylate bridge.

This motif is common in crystal structures containing Arg, as illustrated by those of Arg acetate ${ }^{41}$ and of the dipeptide L-Arg$\mathrm{L}-\mathrm{Glu}{ }^{42}$ Anionic clusters of general formula $[n A r g+x \mathrm{X}-\mathrm{H}]^{-}$, where $n=1-9$ for $x=1$ with $X=$ Glu or Asp, have been observed in the gas phase. ${ }^{43}$ Theoretical DFT calculations (including the effect of water as a solvent) indicate that the preferred arrangements of Arg / amino acid pairs are those where it is possible to establish guanidinium-carboxylate bridges like that of Figure 1. The strongest interactions $(\Delta \mathrm{E}=-$ $35.6 \mathrm{kcal} \mathrm{mol}^{-1}$ ) are with the carboxylate group of $\mathrm{Glu} .{ }^{44}$ In fact, it has been shown that the well-known property of equimolar, relatively concentrated Arg/Glu aqueous solutions of enhancing the solubility of poorly soluble proteins up to $4-8$ times $^{45}$ is due to the formation of a structured, hydrogen-bonded molecular polyelectrolyte mixture. ${ }^{46,47}$

Bearing these precedents in mind, set out to study the catalytic properties of Arg/Glu mixtures, taking as a benchmark reaction the aldol addition of cyclohexanone (1) to 4-nitrobenzaldehyde (2), as a promising system for the observation of cooperative effects between two different $\alpha$-amino acids in the catalysis of the aldol reaction.

\section{Materials and Methods}

\section{General methods}

All reactions were carried out in small vials open to air atmosphere, and under magnetic stirring. Solvents (DMSO, ACS spectrophotometric grade), and commercially available reagents and catalysts were purchased from Sigma-Aldrich and used as received. $\mathrm{N}$-Boc-L-Glu was prepared from L-Glu according to a standard literature procedure $\left(\mathrm{Boc}_{2} \mathrm{O}, \mathrm{NEt}_{3}, \mathrm{DMF}, 1 \mathrm{~h}, \mathrm{rt}\right) .{ }^{48}{ }^{1} \mathrm{H}$ NMR spectra $(400 \mathrm{MHz})$ were recorded in $\mathrm{CDCl}_{3}$ at room temperature on a Varian Mercury 400 instrument. Chemical shifts (d) are given in ppm relative to tetramethylsylane (TMS) and coupling constants $(J)$ are given in Hz. HPLC analyses were performed on a Shimadzu instrument containing LC-20-AD solvent delivery unit, DGU-20AS degasser unit and SPD-M20A UV/VIS Photodiode Array detector, with chiral stationary phase (Daicel Chiralpak ${ }^{\circledR}$ IB column).

Typical experimental procedure for the study of the glutamic acid-arginine system in the aldol reaction

A suspension of L-Glu, L-Arg, or a mixture of them (total amount $0.12 \mathrm{mmol})$ in a solution of cyclohexanone $1(0.20 \mathrm{~g}, 2.0 \mathrm{mmol})$ in aqueous DMSO $\left(0.4 \mathrm{~mL}, 3.5 \mathrm{vol} \% \mathrm{H}_{2} \mathrm{O}\right)$ was stirred at rt for 30 min. Next, 4-nitrobenzaldehyde $2(62 \mathrm{mg}, 0.41 \mathrm{mmol})$ was added in a single portion and stirring was continued for $16 \mathrm{~h}$. At this point, a sample of the reaction mixture was analyzed by ${ }^{1} \mathrm{H}$ NMR. Ethyl acetate $(5 \mathrm{~mL})$ was added and the resulting solution was washed with aqueous saturated $\mathrm{NH}_{4} \mathrm{Cl}(5 \mathrm{~mL})$. The aqueous phase was extracted with ethyl acetate $(2 \times 5 \mathrm{~mL})$ and the combined organic layers were washed with brine $(10 \mathrm{~mL})$, and dried over $\mathrm{MgSO}_{4}$. The solvent was removed in vacuo and the resulting solid was analyzed by HPLC, using as reference the racemic and enantioenriched material obtained by catalysis with proline. $^{8}$

$\left(S^{*}\right)$-2-(($\left.S^{*}\right)$-Hydroxy-(4-nitrophenyl)methyl)cyclohexan-1-

one, $3 .{ }^{49}{ }^{1} \mathrm{H}$ NMR $\left(400 \mathrm{MHz}, \mathrm{CDCl}_{3}, \mathrm{TMS}_{\text {int }}\right): \mathrm{d} 8.21(\mathrm{~d}, J=8.8$, $2 \mathrm{H}) ; 7.49(\mathrm{~d}, J=8.8,2 \mathrm{H}) ; 5.48(\mathrm{~m}, 1 \mathrm{H}) ; 3.16(\mathrm{~d}, J=3.4,1 \mathrm{H}$, $\mathrm{OH})$; 2.67-2.59 (m, 1H); 2.54-2.45 (m, 1H); 1.80-1.44 (m, 4H). HPLC (Chiralpak ${ }^{\circledR}$ IB, $1 \mathrm{~mL} / \mathrm{min}$, hexane:IPA 95:5, $\left.270 \mathrm{~nm}\right): \mathrm{t}_{\mathrm{R}}=$ $20.5 \mathrm{~min}\left(1^{\prime} R, 2 R\right), 23.0 \mathrm{~min}\left(1^{\prime} S, 2 S\right)$.

$\left(S^{\star}\right)$-2-(( $\left.R^{\star}\right)$-Hydroxy-(4-nitrophenyl)methyl)cyclohexan-1one, $4 .{ }^{49}{ }^{1} \mathrm{H}$ NMR $\left(400 \mathrm{MHz}, \mathrm{CDCl}_{3}, \mathrm{TMS}_{\text {int }}\right)$ : d 8.21 (d, $J=8.7$, $2 \mathrm{H}) ; 7.51$ (d, $J=8.7,2 \mathrm{H}) ; 4.90\left(\mathrm{dd}, J=8.5, J^{\prime}=3.1,1 \mathrm{H}\right) ; 4.06$ $(\mathrm{d}, J=3.1,1 \mathrm{H}, \mathrm{OH}) ; 2.64-2.54(\mathrm{~m}, 1 \mathrm{H}) ; 2.54-2.45(\mathrm{~m}, 1 \mathrm{H}) ; 2.44-$ $2.28(\mathrm{~m}, 1 \mathrm{H}) ; 2.16-2.08(\mathrm{~m}, 1 \mathrm{H}) ; 1.87-1.79(\mathrm{~m}, 1 \mathrm{H}) ; 1.64-1.45$ $(\mathrm{m}, 1 \mathrm{H}) . \mathrm{HPLC}\left(\right.$ Chiralpak $^{\circledR} \mathrm{IB}, 1 \mathrm{~mL} / \mathrm{min}$, hexane:IPA 95:5, 270 $\mathrm{nm}): \mathrm{t}_{\mathrm{R}}=26.0 \mathrm{~min}\left(1^{\prime} R, 2 S\right), 32.3 \mathrm{~min}\left(1^{\prime} S, 2 R\right)$.

(E)-2-(4-Nitrobenzylidene)cyclohexan-1-one, $\quad 5^{50}{ }^{1} \mathrm{H} \quad \mathrm{NMR}$ $\left(400 \mathrm{MHz}, \mathrm{CDCl}_{3}, \mathrm{TMS}_{\text {int }}\right): \mathrm{d} 8.24(\mathrm{~d}, J=8.8,2 \mathrm{H}) ; 7.52(\mathrm{~d}, J=$ $8.8,2 \mathrm{H}) ; 7.52(\mathrm{t}, J=2.2,1 \mathrm{H}) ; 2.83(\mathrm{~m}, 2 \mathrm{H}) ; 2.59(\mathrm{t}, J=6.6,2 \mathrm{H})$; $1.98(\mathrm{~m}, 2 \mathrm{H}) ; 1.82(\mathrm{~m}, 2 \mathrm{H})$.

\section{Results and Discussion}

As the first model reaction for our study, we selected the aldol reaction of cyclohexanone (1, $5 \mathrm{~mol}$ equiv.) with 4nitrobenzaldehyde $(2,0.65 \mathrm{M})$, both in dry and in aqueous (3.5 vol\% of $\mathrm{H}_{2} \mathrm{O}$ ) DMSO at r.t. and in the presence of a $30 \mathrm{~mol} \%$ amount of amino acid catalyst, conditions very similar to those used by Hayashi in his survey of the effectiveness of proteinogenic amino acids in the asymmetric aldol reaction. ${ }^{21}$ After $16 \mathrm{~h}$ of stirring, the reaction crude was analyzed both by ${ }^{1} \mathrm{H}$ NMR and (after aqueous work-up and extraction), by chiral HPLC. The observed reaction products were the syn-aldol (3), the anti-aldol (4) and the dehydrated aldol (5), and the catalysts used were L-Arg and L-Glu (Scheme 1). According to the ${ }^{1} \mathrm{H}$ NMR spectra of the crude reaction mixtures, the dehydrated aldol 5 was the main product (ca. $60 \%$ of the products mixture) in the reactions catalyzed both by L-Arg and by the $1: 1 \mathrm{~L}-\mathrm{Arg} / \mathrm{L}-$ Glu catalyst mixture, while it could not be detected when L-Glu alone was used as the catalyst.

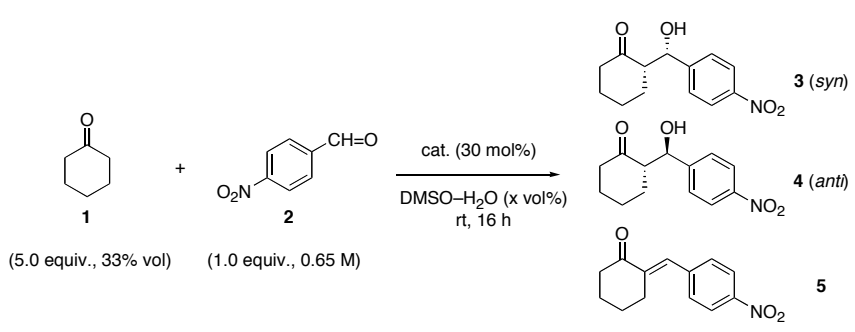

SCHEME 1 Amino acid-catalyzed aldol reaction between cyclohexanone (1) and 4-nitrobenzaldehyde (2).

The main results concerning the aldol products are summarized 
in Table 1. The absolute configurations of the major enantiomers of the two aldol adducts were assigned by comparison with those obtained with L-Pro ((2S,1'S) for 3 and $\left(2 S, 1^{\prime} R\right)$ for 4$){ }^{8,51}$

TABLE 1 Initial study of the cooperative effects between L-Arg and L-Glu in the aldol reaction.

\begin{tabular}{|c|c|c|c|c|c|}
\hline Entry & Catalyst & $x$ vol\% $\mathrm{H}_{2} \mathrm{O}$ & $3: 4^{a}$ & $\%$ ee $3^{b}$ & $\%$ ee $4^{b}$ \\
\hline 1 & L-Arg & 0 & $1.2: 1.0$ & $-21^{c}$ & 52 \\
\hline 2 & L-Glu & 0 & $1.0: 2.3$ & 32 & 67 \\
\hline 3 & 1:1 L-Arg/L-Glu & 0 & $1.0: 1.5$ & $-17^{c}$ & 37 \\
\hline 4 & L-Arg & 3.5 & $1.2: 1.0$ & $-25^{c}$ & 9 \\
\hline 5 & L-Glu & 3.5 & $1.0: 11$ & 11 & 33 \\
\hline 6 & 1:1 L-Arg/L-Glu & 3.5 & $1.0: 2.0$ & $-27^{c}$ & 63 \\
\hline
\end{tabular}

a Determined by ${ }^{1} \mathrm{H}$ NMR of the unpurified reaction mixture. ${ }^{\mathrm{b}} \mathrm{By}$ chiral HPLC (Chiralpak ${ }^{\circledR}$ IB column). ${ }^{\complement}$ The major enantiomer has a $\left(2 R, 1^{\prime} R\right)$ configuration).

As it can be seen, the stereochemical outcome of the reaction depends on the solvent used, but our attention was caught by the observation that in wet $\left(3.5 \mathrm{vol} \% \mathrm{H}_{2} \mathrm{O}\right)$ DMSO, the enantiomeric excesses both of the syn isomer 3 and of the anti isomer 4 were higher when we used an equimolar mixture of LArg and L-Glu as the catalyst (entry 6) than either for L-Arg (entry 4) or for L-Glu (entry 5) alone. Other solvents (pure $\mathrm{H}_{2} \mathrm{O}$, $\mathrm{CH}_{2} \mathrm{Cl}_{2}, \mathrm{MeOH}$, THF) were also examined, but the low solubility of pure L-Glu in all of them precluded the observation of any cooperative effect.

On the other hand, when the reactions were performed in dry DMF, in which both aminoacids are soluble, no aldol products were detected after $16 \mathrm{~h}$ at rt. We decided therefore to take a closer look at the catalytic activity of Arg-Glu mixtures on this aldol reaction in aqueous DMSO.

The stereochemical outcome of the benchmark aldol reaction between cyclohexanone (1, 5.0 equiv.) and 4-nitrobenzaldehyde (2) was examined for different L-Arg/L-Glu ratios in DMSO / $\mathrm{H}_{2} \mathrm{O}$ (3.5 vol\%), but otherwise in the conditions of Eq. 1 (15 mol\% of catalyst, $0.65 \mathrm{M} \mathrm{1,16} \mathrm{h,} \mathrm{rt).} \mathrm{The} \mathrm{results} \mathrm{are} \mathrm{depicted} \mathrm{in} \mathrm{Figures}$ $2 \mathrm{~A}, 2 \mathrm{~B}$ and $2 \mathrm{C}$.

The anti/syn (4:3) ratio, plotted in Figure $2 \mathrm{~A}$ as $\%$ of anti isomer 4 vs. \% of L-Arg in the catalyst mixture, diminishes linearly from $11: 1(91.6 \%$ of 4$)$ for pure L-Glu to $1: 1.2(45.5 \%$ of 4) for pure L-Arg. Interestingly enough, however, the enantiomeric excess of 4 reaches a maximum (63\% ee) for $50 \%$ L-Arg (Figure 2B), clearly showing a positive cooperative effect between both amino acids. For the syn diastereomer 3 (Figure $2 \mathrm{C}$ ) a cooperative effect is also evinced, although in this case a maximum ee is reached for a L-Arg/L-Glu ratio close to $2: 1$.

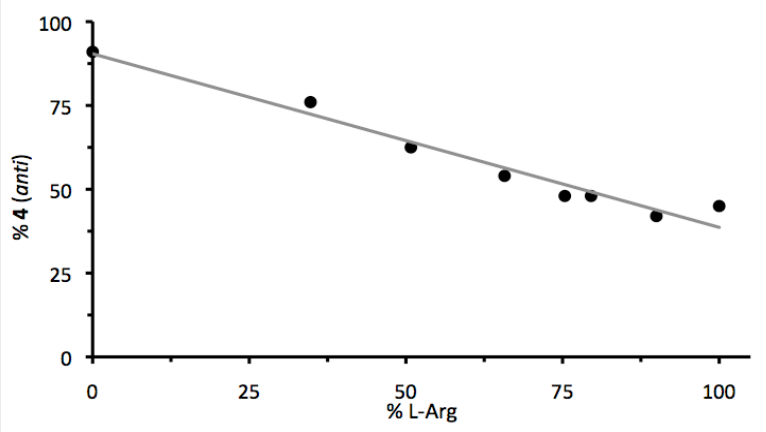

$2 \mathrm{~A}$

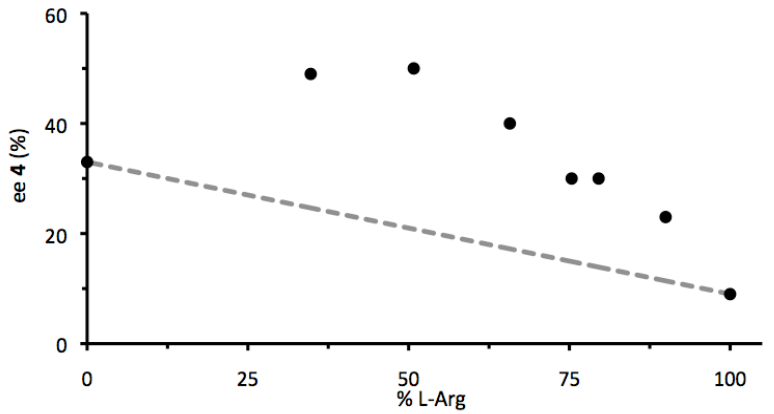

2B

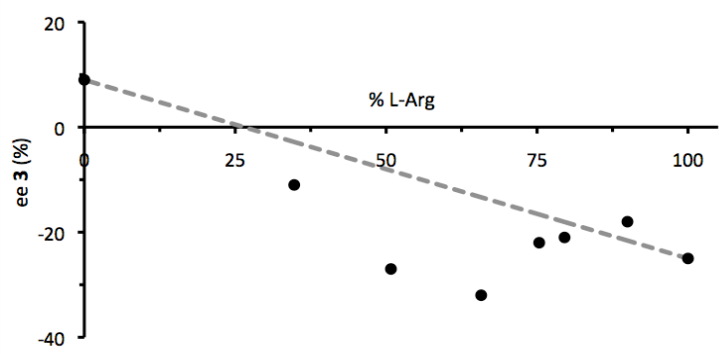

2C

FIGURE 2 Stereochemical outcome of the aldol reaction for increasing $\%$ of L-Arg in the L-Arg/L-Glu catalyst mixture. A: \% of anti aldol 4. B: \% ee of anti aldol 4. C: \% ee of syn aldol 3.

An important observation is that the addition of L-Arg reverses the configuration of the major enantiomer of 3 , from $\left(2 S, 1^{\prime} S\right)$ for pure L-Glu to $\left(2 R, 1^{\prime} R\right)$ in all L-Arg/L-Glu mixtures. This suggests that a catalytically competent mixed species could be acting, in which the active amino group belongs to L-Arg. In order to verify this assumption, we set out to study the catalytic activity of L-Arg / L-Glu mixtures in which one of the amino acids is $\mathrm{N}$-protected. $\mathrm{N}$-acetyl-L-arginine ( $\mathrm{N}$-Ac-L-Arg) is commercially available, and $N$-Boc-L-Glu was prepared by a literature method. ${ }^{48}$<smiles>CC(=O)N[C@@H](CCCNC(=N)N)C(=O)O</smiles><smiles>CCCCOC(=O)N[C@@H](CCC(=O)O)C(=O)O</smiles>

We were pleased to find that, as shown in Table 2, the catalytic activity of a 1:1 L-Arg/ $\mathrm{N}$-Boc-L-Glu mixture is essentially the same than that of the equimolar L-Arg / L-Glu mixture (entries 1 and 2 in Table 2), while when using a 1:1 N-Ac-L-Arg/L-Glu mixture, only a $22 \%$ of the starting aldehyde 2 had reacted after $16 \mathrm{~h}$ at rt, to afford a 3.8:1 mixture of syn- and anti-aldols with low enantioselectivity (entry 3 in Table 2). A further proof of the lack of catalytic activity of the amino group of Glu in the Arg/Glu mixtures was provided by the observation that when L-Glu was replaced either by D-Glu (entry 4 in Table 2 ) or by rac-Glu (entry 5 in Table 2), the results were again similar to those obtained with original L-Arg/L-Glu mixture (entry 1). Finally, we observed that essentially the same results arose when L-Glu was replaced either by acetic acid $(\mathrm{AcOH}$, entry 6 in Table 2$)$ or by adipic acid (entry 7 ). 
TABLE 2 Searching for the active amino group in the L-Arg/L-Glu catalysis of the aldol reaction between 1 and 2 . $^{a}$

\begin{tabular}{cccccc}
\hline Entry & Catalyst & Conversion $^{\mathrm{b}}$ & $\mathbf{3 : 4}^{\mathrm{c}}$ & \%ee $^{\mathrm{d},} \%$ ee $\mathbf{4}^{\mathrm{d}}$ \\
\hline 1 & L-Arg/L-Glu & $100 \%$ & $1.0: 2.0$ & -27 & 63 \\
2 & L-Arg/N-Boc-L-Glu & $98 \%$ & $1.0: 2.0$ & -28 & 57 \\
3 & N-Ac-L-Arg/L-Glu & $22 \%$ & $1.0: 3.8$ & -10 & 10 \\
4 & L-Arg/D-Glu & $100 \%$ & $1.0: 1.9$ & -19 & 35 \\
5 & L-Arg/DL-Glu & $94 \%$ & $1.0: 2.4$ & -12 & 52 \\
6 & L-Arg/AcOH & $99 \%$ & $1.0: 1.0$ & -27 & 53 \\
7 & L-Arg/Adipic acid & $98 \%$ & $1.0: 1.1$ & -37 & 50 \\
\hline
\end{tabular}

${ }^{a}$ Reaction conditions: $2 \mathrm{mmol}$ cyclohexanone (1), $0.41 \mathrm{mmol} 4-$ nitrobenzaldehide (2), $0.06 \mathrm{mmol}$ of each component of the catalyst mixture, $0.4 \mathrm{~mL}$ aq. DMSO $\left(3.5 \mathrm{vol} \% \mathrm{H}_{2} \mathrm{O}\right)$, rt, $16 \mathrm{~h}$.

${ }^{\mathrm{b}}$ Conversion (\%) of aldehyde 2 , measured by ${ }^{1} \mathrm{H}$ NMR of the reaction mixture. ${ }^{\circ}$ Determined by ${ }^{1} \mathrm{H}$ NMR of the unpurified reaction mixture. ${ }^{\mathrm{d}}$ By chiral HPLC (Chiralpak ${ }^{\circledR}$ IB column); the major enantiomer of the syn-aldol 3 has a $\left(2 R, 1^{\prime} R\right)$ configuration.

In summary, all of the available evidences suggest that the active catalytic species in the L-Arg/L-Glu mixture has the structure depicted at the top of Figure 3, in which the amino group of Glu is protonated while that of Arg is free and can participate in the enamine catalysis. It is worth noting that the formation of a guanidinium-carboxylate bridge from the most stable zwitterionic forms of L-Arg and L-Glu would directly lead to a catalytically inactive dimer, in which the $\alpha$-carboxylic acid group of L-Arg is not protonated, so that a proton transfer from the carboxylic acid of the lateral chain of L-Glu is needed to form a species that can catalyze the aldol reaction. This could explain why no cooperative effect is apparent in the absence of water (entries 1-3 in Table 1), that is necessary for a fast proton transfer from L-Glu to L-Arg.

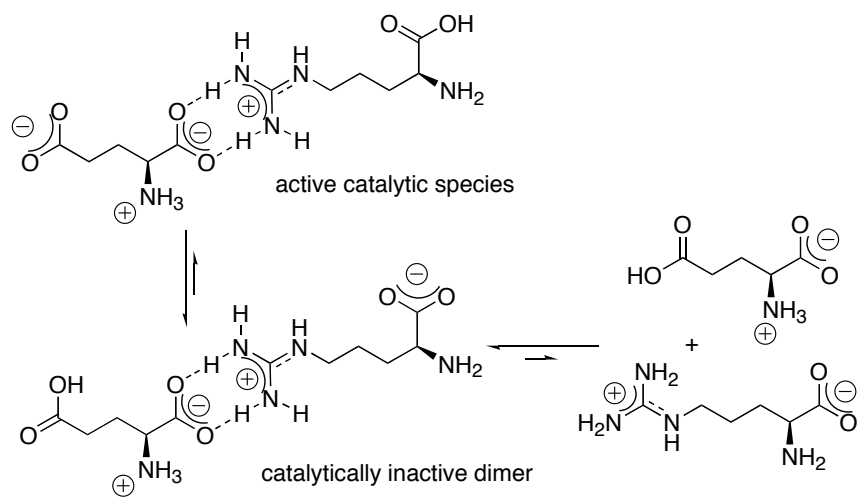

FIGURE 3 Proposed mechanism for the formation of a catalytically active dimer species in L-Arg/L-Glu mixtures.

We decided next to monitor the progress of the reaction, in order both to establish accurately the time necessary to achieve total conversion and to follow how the yields and the enantiomeric excesses (for $\mathbf{3}$ and $\mathbf{4}$ ) of the reaction products (syn-aldol $\mathbf{3}$, antialdol 4 and elimination product 5) change with time. We found that this could be conveniently done by direct HPLC analysis (Chiralpak ${ }^{\circledR}$ IB column) of reaction mixture samples taken off at different times, by using 2,7-dimethoxynaphthalene (16 mol\%) as an internal standard, in the reaction conditions of Scheme 1 (see also footnote $a$ in Table 2). We had previously used this methodology in our analysis of spontaneous mirror-symmetry breaking in the aldol reaction between acetone and 4nitrobenzaldehyde (2). ${ }^{52}$

The kinetic study of the catalysis of the aldol reaction between 1 and 2 by L-Glu (30 mol\%) in aqueous DMSO (3.5 vol\% $\mathrm{H}_{2} \mathrm{O}$ ) showed, after a small induction period of 1-2 $\mathrm{h}$, an exponential decrease on the concentration of 4-nitrobenzaldehyde (2), and $90 \%$ conversion was reached after $9 \mathrm{~h}$ (Figure $4 \mathrm{~A}$ ). After $25 \mathrm{~h}$, no starting aldehyde could be detected in the reaction mixture. At the same time, the global concentration of aldol products $(3+$ 4 ) increased exponentially, and the yield of elimination product 5 remained very small (less than 1\%). The 1:11 diastereomeric ratio (3:4) was kept constant during all of the reaction time, but we were surprised to find that when we measured the solution enantiomeric excess of both diastereomers in the first hours of the reaction (see Figure 4B), we found out that they decreased exponentially, from initial values of $36 \%$ ee (for the syn-adduct 3 ) and of $73 \%$ ee (for the major anti-adduct 4). The final measured values (after $8 \mathrm{~h}$ ) were of $11 \%$ ee (3) and of $30 \%$ ee (4), very close to those we had determined previously for the isolated aldol mixture after $16 \mathrm{~h}\left(100 \%\right.$ conversion by ${ }^{1} \mathrm{H}$ NMR, entry 5 in Table 1). This result could be indicative of a kinetic resolution of the aldol adducts by L-Glu, similar to those observed by Blackmond and co-workers in some proline-catalyzed reactions. ${ }^{53,54}$

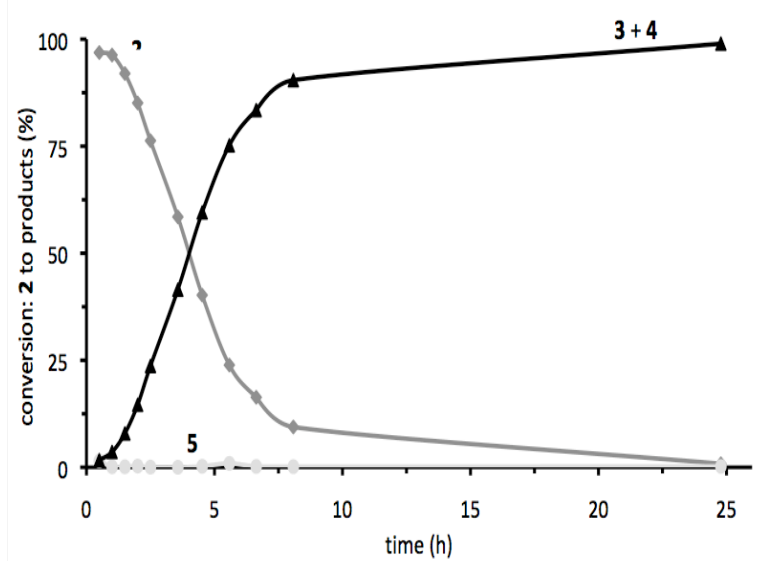

$4 \mathrm{~A}$

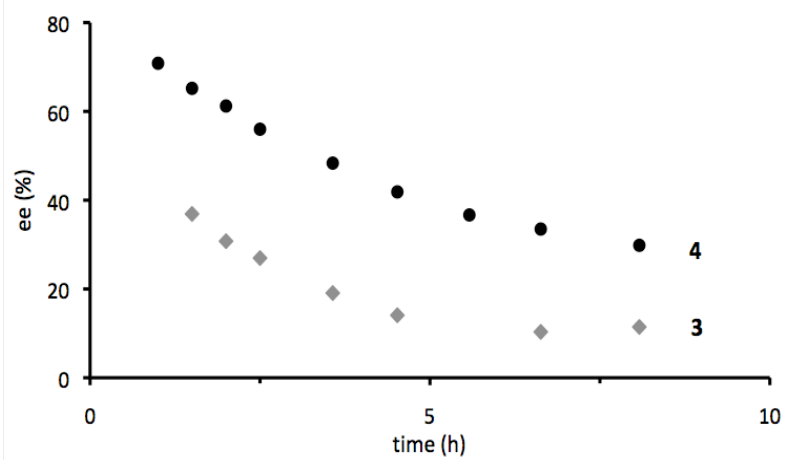

$4 \mathrm{~B}$

FIGURE 4 Kinetic analysis of the L-Glu catalysis of the aldol reaction between 1 and 2. A: Evolution of the concentrations (normalized) of the starting aldehyde $(2)$ and the reaction products $(3+4,5)$ with time. B: Variation of the solution enantiomeric purity of the syn-aldol 3 and of the anti-aldol 4 during the first $8 \mathrm{~h}$ of the reaction.

The monitoring of the catalysis of the same reaction by L-Arg (30 $\mathrm{mol} \%$ ) in the same conditions showed that after $7 \mathrm{~h}$ no starting aldehyde 2 remained in the reaction mixture, and that the major 
reaction product was the dehydrated aldol 5 (Figure 5). It is worth noting that $\mathbf{5}$ is formed more rapidly than the aldol adducts $3 / 4$, and that the aldol:elimination product ratio remains constant after the total consumption of the aldehyde, so that $\mathbf{5}$ is not formed by dehydration of the aldol adducts. Moreover, neither the 1.2:1 3:4 syn/anti ratio nor (within experimental error) the enantiomeric purities of both diastereomers did change with conversion. All of this suggests that both $\mathbf{3}, \mathbf{4}$, and $\mathbf{5}$ arise from a common intermediate, probably the imine $\mathbf{6}$, in which the guanidium cation moiety can promote the dehydration of the aldol adducts (Scheme 2).

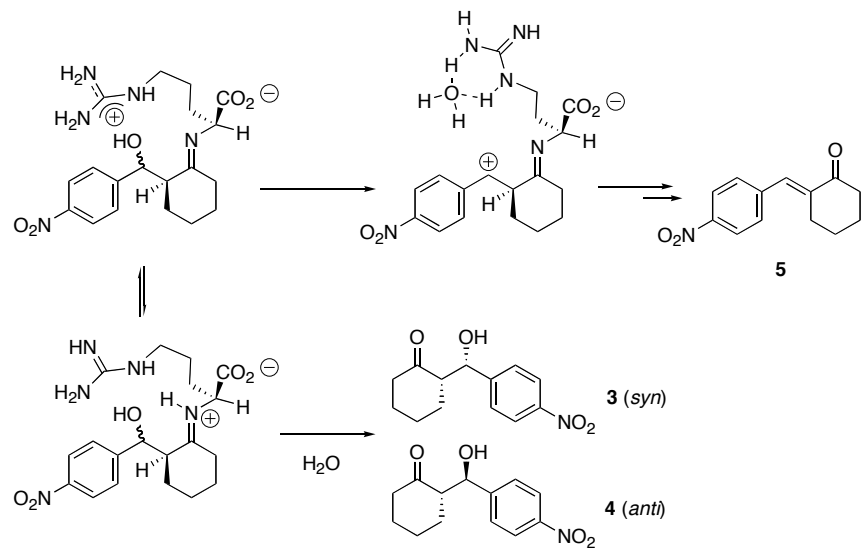

SCHEME 2 Proposed mechanism for the formation of the dehydrated aldol $\mathbf{5}$ under catalysis by L-Arg.

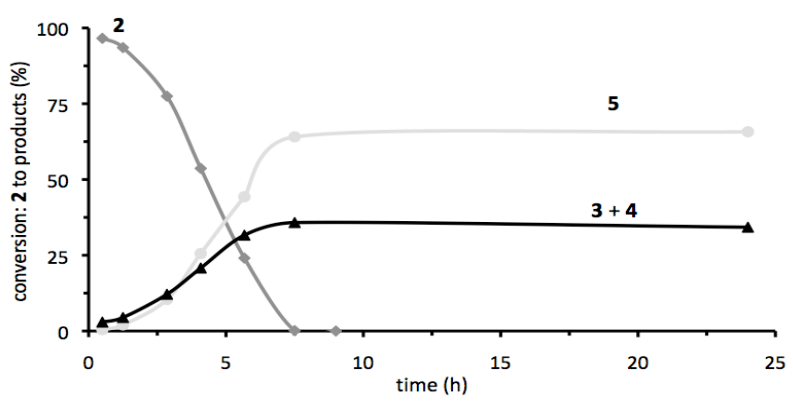

FIGURE 5 Kinetic analysis of the L-Arg catalysis of the aldol reaction between 1 and 2 .

The kinetic profile of the reaction catalyzed by the $1: 1 \mathrm{~L}-\mathrm{Arg} / \mathrm{L}-$ glu mixture (15 mol\% each) is depicted in Figure 6 . Similar to the catalysis by L-Arg alone, conversion was complete after $7 \mathrm{~h}$ and the dehydrated aldol 5 also was the major product (ca. $66 \%$ of the reaction mixture). However, in this case the amount of aldol adducts $(3+4)$ was somewhat higher then for L-Arg $(33 \%$ vs. $25 \%$ of the reaction mixture, respectively). This ratio did not change appreciably after the disappearance of the starting aldehyde. It is worth noting that since the catalytic activity arises only from L-Arg, this result implies that the complex with L-Glu shows a $100 \%$ increase in the catalytic efficiency.

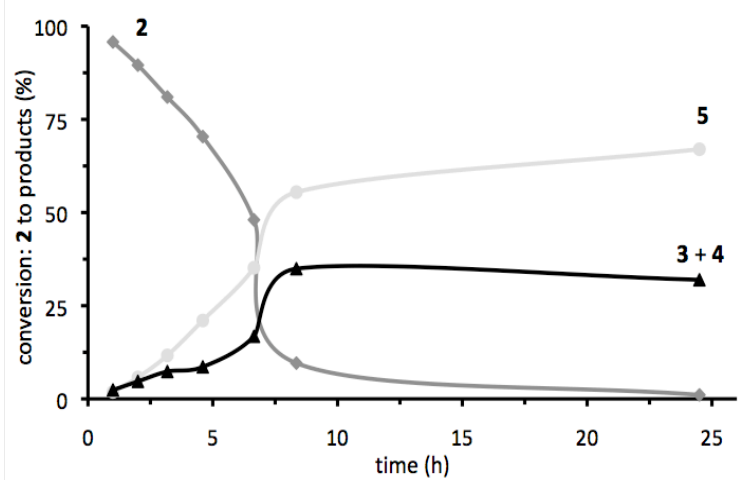

FIGURE 6 Kinetic analysis of the L-Arg/L-Glu catalysis of the aldol reaction between 1 and 2 .

We could also see that the 1:2 syn/anti diastereomer ratio remained constant throughout the reaction. On the other hand, when we monitored the enantiomeric purity of the aldol products, we found out that the enantiomeric purity of the syn adduct 3 (ca. $30 \%$ ee for the $\left(2 R, 1^{\prime} R\right)$ isomer) remained constant during the first 5 hours of reaction. Meanwhile, the enantiomeric purity of the anti aldol 4 increased with time, from a $20 \%$ ee measured after $1 \mathrm{~h}$ to a maximum $55 \%$ ee after 5 hours. In order to check if this increase in the enantiomeric purity of the anti aldol $\mathbf{4}$ in the first hours of the reaction was due to a selective kinetic resolution by the L-Arg/L-Glu catalyst, we monitored the evolution of a $0.33 \mathrm{M}$ solution of a $54: 1$ antisyn (4:3) mixture (racemic, obtained by the DL-proline-catalyzed reaction between 1 and 2) in aqueous DMSO, in the presence of a $15 \mathrm{~mol} \%$ of LArg and of a $15 \mathrm{~mol} \%$ of L-Glu. We observed that, as expected, only very minor amounts of $\mathbf{5}$ were formed (less than $10 \%$ after $27 \mathrm{~h}$ ), and that the aldol products remained racemic during the experiment. On the other hand, the diastereomeric ratio of the aldol products 3 and $\mathbf{4}$ changed slowly with time, and a ca. 1.6:1 anti:syn ratio was measured after $27 \mathrm{~h}$. Therefore, the 2:1 anti:syn ratio observed in the reaction must arise from kinetic control, strongly suggesting that the 1:1 L-Arg/L-Glu complex exhibits a characteristic catalytic behaviour in the aldol reaction.

\section{Conclusion}

In summary, the present results show that an equimolar L-Arg/LGlu mixture in wet DMSO gives rise to a distinct catalytic species, with a behaviour clearly different from that expected if both aminoacids catalyzed independently the aldol reaction. To the best of our knowledge, this represents the first example of cooperative effects between different proteinogenic $\alpha$-amino acids in the catalysis of the aldol reaction. In particular, the observation of a seven-fold enhancement in the enantiomeric purity of the anti-aldol 4 in the L-Arg-catalyzed reaction between 1 and 2 by the presence of equimolecular amounts of L-Glu (from $9 \%$ ee to $63 \%$ ee) suggests that prebiotic amplification of chirality could have taken place by cooperative effects between amino acids in the complex mixtures present in carbonaceous chondrites. 


\section{Acknowledgements}

G.V. thanks the Spanish Ministry of Economy and Competitivity (MINECO) for a FPI predoctoral fellowship. Financial support from MINECO (Project CTQ2013-47401-C2-1-P) and participation in the COST Action CM0905 are gratefully acknowledged. We also thank Dr. M. Pons (UB) for drawing our attention to the protein-solubilizing properties of L-Arg/L-Glu mixtures.

\section{Supporting information}

Additional supporting information (selected HPLC traces of compounds $\mathbf{3}$ and $\mathbf{4}$ ) may be found in the online version of this article at the publisher's website. [a] Dr. Guillem Valero, Prof. Albert Moyano Departament de Química Orgànica

Universitat de Barcelona

Facultat de Química, C. Martí i Franquès 1-11, 08028 -

Barcelona, Catalonia, Spain.

E-mail (A. Moyano): amoyano@ub.edu

Received: ((will be filled in by the editorial staff))

Revised: ((will be filled in by the editorial staff))

Published online: ((will be filled in by the editorial staff))

\section{REFERENCES AND NOTES}

1. Mahrwald R, editor. Modern Aldol Reactions, Vols. 1 \& 2. Weinheim: Wiley-VCH; 2004.

2. Fessner WD. Enzymatic asymmetric synthesis using aldolases. In: Patel RN, editor. Stereoselective Biocatalysis. New York: Marcel Dekker; 2000, p. 239-265.

3. Fesko K, Gruber-Khadjawi M. Biocatalytic methods for C-C bond formation. ChemCatChem 2013; 5:1248-1272.

4. Alcaide B, Almendros $P$. The direct catalytic asymmetric aldol reaction. Eur. J. Org. Chem. 2002; 1595-1601.

5. Notz W, Tanaka S, Barbas III CF. Enamine-based organocatalysis with proline and diamines: The development of direct catalytic asymmetric aldol, Mannich, Michael, and DielsAlder reactions. Acc. Chem. Res. 2004; 37: 580-591.

6. Mukherjee S, Yang JW, Hoffmann S, List B. Asymmetric enamine catalysis. Chem. Rev. 2007; 107: 5471-5569.

7. Trost BM, Brindle CS. The direct catalytic asymmetric aldol reaction. Chem. Soc. Rev. 2010; 39: 1600-1632.

8. List B, Lerner RA, Barbas III CF. Proline-catalyzed direct asymmetric aldol reactions. J. Am. Chem. Soc. 2000; 122: 23952396.

9. Sakthivel KS, Notz W, Bui T, Barbas III CF. Amino acid catalyzed direct asymmetric aldol reactions: A bioorganic approach to catalytic asymmetric carbon-carbon bond-forming reactions. J. Am. Chem. Soc. 2001; 123: 5260-5267.

10. Barbas III CF. Organocatalysis lost: modern chemistry, ancient chemistry, and an unseen biosynthetic apparatus. Angew. Chem. Int. Ed. 2008; 47: 42-47.

11. Guillena G, Nájera C, Ramon DJ. Tetrahedron: Asymmetry, 2007; 18: 2249;

12. Zlotin GS, Kucherenko AS, Beletskaya IP. Organocatalysis of asymmetric aldol reaction. Catalysts and reagents. Russ. Chem. Rev. 2009; 78: 737-784.

13. Valero G, Companyó X, Bravo N, Alba A-NR, Moyano A, Rios R. Searching for untrodden paths in organocatalysis territory. Synlett 2010; 1883-1908.

14. Mlinarsky J, Gut B. Organocatalytic synthesis of carbohydrates. Chem. Soc. Rev. 2012; 41: 587-596.

15. Gryko D, Walaszek, D. C-C bond formation by aldol reaction. In: Rios Torres, R, editor. Stereoselective Organocatalysis. Hoboken: John Wiley \& Sons; 2013. p. 81-127. 16. Mase N, Barbas III CF. Aldol and Mannich-type reactions. In: Dalko PI, editor. Comprehensive Enantioselective Organocatalysis, Vol. 3: Reactions and Applications. Weinheim: Wiley-VCH; 2013. p. 793-840.

17. Amedjkouh M. Primary amine catalyzed direct asymmetric aldol reaction assisted by water. Tetrahedron: Asymmetry 2005; 16: $1411-1414$.

18. Córdova A, Zou W, Ibrahem I, Reyes E, Engqvist M, Liao WW. Acyclic amino acid-catalyzed direct asymmetric aldol reactions: alanine, the simplest enantioselective organocatalyst. Chem. Commmun. 2005; 3586-3588. 
19. Córdova A, Zou W, Dziedzic P, Ibrahem I, Reyes E, Xu Y. Direct asymmetric aldol reactions catalyzed by amino acids and small peptides. Chem. Eur. J. 2006; 12: 5383-5397.

20. Tsogoeva SB, Wei S. (S)-Histidine-based dipeptides as organic catalysts for direct asymmetric aldol reactions. Tetrahedron: Asymmetry 2005; 16: 1947-1951.

21. Hayashi $Y$, Itoh $T$, Nagae $N$, Ohkubo $M$, Ishikawa $H$. The effectiveness of proteinogenic amino acids in the asymmetric aldol reaction in DMSO and aqueous DMSO. Synlett 2008; 1565-1570.

22. Jiang $Z$, Yang $H$, Han $X$, Luo J, Wong MW, Lu Y. Direct asymmetric aldol reactions between aldehydes and ketones catalyzed by L-tryptophan in the presence of water. Org. Biomol. Chem. 2010; 8: 1368-1377.

23. Deng D, Liu P, Ji B, Fu W, Li L. Acyclic amino acids catalyzed direct asymmetric aldol reactions in aqueous media assisted by 2,4-dinitrophenol. Catal. Lett. 2010: 137: 163-170.

24. Deng D-S, Cai J. Stereoselective aldol reactions catalyzed by acyclic amino acids in aqueous micelles. Helv. Chim. Acta 2007: 90: 114-120.

25. Lombardo M, Easwar S, Pasi F, Trombini C, Dhavale DD. Protonated arginine and lysine as catalysts for the direct asymmetric aldol reaction in ionic liquids. Tetrahedron 2008; 64: 9203-9207.

26. Bonner W. The origin and amplification of molecular chirality. Orig. Life Evol. Biosphere 1991; 21: 59-111.

27. Luisi PL. The Emergence of Life-From Chemical Origins to Synthetic Biology. Cambridge: Cambridge University Press; 2006.

28. Guijarro A, Yus M. The Origin of Chirality in the Molecules of Life. Cambridge: The Royal Society of Chemistry; 2009.

29. Ávalos M, Babiano R, Cintas $P$, Jiménez JL, Palacio JC. Homochirality and chemical evolution: new vistas and reflections. Tetrahedron: Asymmetry 2010; 21: 1030.

30. Chyba C, Sagan C. Endogenous production, exogenous delivery and impact-shock synthesis of organic molecules: an inventory for the origins of life. Nature 1992; 355: 125-132.

31. Cronin JR, Pizzarello S. Enantiomeric excesses in meteoritic amino acids. Science 1997; 275: 951-955.

32. Cronin JR, Pizzarello S. Amino acid enantiomer excesses in meteorites: origin and significance. Adv. Space Res. 1999; 23 : 293-299.

33. Pizzarello S, Huang Y, Alexandre MR. Molecular Asymmetry in extraterrestrial chemistry: Insights from a pristine meteorite. Proc. Natl. Acad. Sci. USA 2008; 105: 3700-3704.

34. Pizzarello $S$, Weber AL. Prebiotic amino acids as asymmetric catalysts. Science 2004; 303: 1151.

35 Glavin DP, Elsila JE, Burton AS, Callahan MP, Dworkin JP, Hilts RW, Herd CDK. Unusual nonterrestrial L-proteinogenic amino acid excesses in the Tagish Lake meteorite. Meteorit. Planet. Sci. 2012; 47: 1347-1364.

36. Moyano A. Activation modes in asymmetric organocatalysis. In: Rios Torres, R, editor. Stereoselective Organocatalysis. Hoboken: John Wiley \& Sons; 2013. p. 11-80.

37. Hunter EP, Lias SG. Arginine. In: Mallard WG, Lindstrom PJ, editors. NIST Chemistry WebBook, NIST Standard Reference Database Number 69. National Institute of Standards and Technology;

(http://webbook.nist.gov/cgi/cbook.cgi?ID=C74793\&Mask=20)

38. Maksic ZB, Kovacevic B. Neutral vs. zwitterionic form of arginine - and $a b$ initio study. J. Chem. Soc., Perkin Trans. 2 1999; 2623-2629.

39. Chapo CJ, Paul JB, Provencal RA, Roth K, Saykally J. Is arginine zwitterionic or neutral in the gas phase? J. Am. Chem. Soc. 1998; 120: 12956-12957.
40. Karle IL, Karle J. An application of the symbolic addition method to the structure of L-arginine dihydrate. Acta Cryst. 1964; 17: 835-841.

41. Suresh CG, Vijayan M. X-ray studies on crystalline complexes involving amino acids and peptides. VIII. Head-to-tail arrangement and a specific interaction in the crystal structure of L-arginine acetate. Int. J. Peptide Protein Res. 1983; 21: 223226.

42. Bhat TN, Vijayan M. X-ray studies on crystalline complexes involving amino acids. II. The crystal structure of L-arginine Lglutamate. Acta Cryst. 1977; B33: 1754-1759.

43. Julian RR, Hodyss R, Beauchamp JL. Salt bridge stabilization of charged zwitterionic arginine aggregates in the gas phase. J. Am. Chem. Soc. 2001; 123: 3577-3583.

44. Shah D. Molecular Insights into the Role of Arginine on Protein Stabilization. PhD Thesis, National University of Singapore; 2011. Available from Lambert Academic Publishing, ISBN-13: 978-3846511152.

45. Golovanov AP, Hauteberge GM, Wilson SA, Yian L-Y. A simple method for improving protein solubility and long-term stability. J. Am. Chem. Soc. 2004; 126: 8933-8939.

46. Blobel J, Brath U, Bernadó P, Diehl C, Ballester L, Sornosa A, Akke M, Pons M. Protein loop compaction and the origin of the effect of arginine and glutamic acid mixtures on solubility, stability and transient oligomerization of proteins. Eur. J. Biophys. 2011; 40: 1327-1338.

47. Shukla D, Trout BM. Understanding the synergistic effect of arginine and glutamic acid mixtures on protein stability. J. Phys. Chem B 2011; 115: 11831-11839.

48. De Cat I, Gobbo C, Van Averbeke B, Lazzaroni R, De Feyter $\mathrm{S}$, van Esch J. Controlling the position of functional groups at the liquid/solid interface: impact of molecular symmetry and chirality. J. Am. Chem. Soc. 2011; 133: 20942-20950.

49. Kanemitsu T, Umehara A, Miyazaki M, Nagata K, Itoh T. L-tleucine-catalyzed direct asymmetric aldol reactions of cyclic ketones. Eur. J. Org. Chem. 2011; 993-997.

50. Das U, Doroudi A, Inci Gul H, Pati HN, Kawase M, Sakagami H, Chu Q, Stables JP, Dimmock JR. Cytotoxic 2-benzylidene-6(nitrobenzylidene)cyclohexanones which display substantially greater toxicity for neoplasms than non-malignant cells. Bioorg. Med. Chem., 2010, 18, 2219-2224.

51. Bahmanyar S, Houk KN, Martin HJ, List B. Quantummechanical predictions of the stereoselectivities of prolinecatalyzed asymmetric intermolecular aldol reactions. J. Am. Chem. Soc. 2003; 125: 2475-2479.

52. Valero G, Ribó JM, Moyano A. A closer look at spontaneous mirror symmetry breaking in aldol reactions. Chem. Eur. J. 2014; 20: $17395-17408$.

53. Mathew SP, Iwamura $\mathrm{H}$, Blackmond DG. Amplification of enantiomeric excess in a proline-mediated reaction. Angew. Chem. Int. Ed. 2004; 43: 3317-3321.

54. Iwamura $\mathrm{H}$, Mathew SP, Blackmond DG. In situ catalyst improvement in the proline-mediated $\alpha$-amination of aldehydes. J. Am. Chem. Soc. 2004; 126: 11770-11771. 

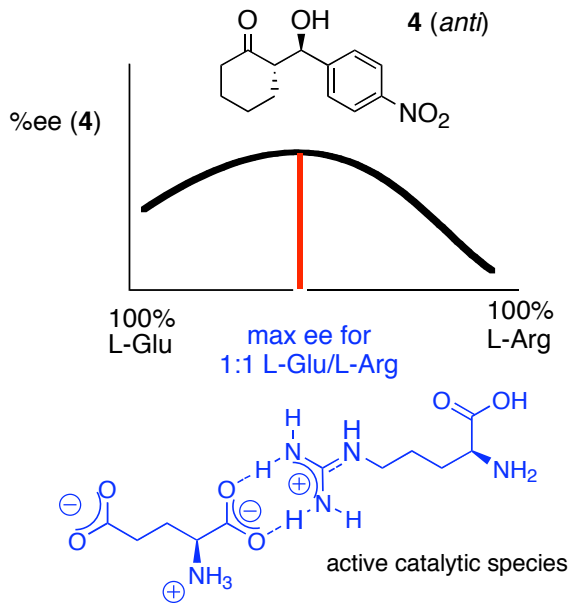

\section{Graphical Abstract}

((A graphical abstract is used in each issue's online graphical table of contents must be included in all manuscripts. The image may be a key figure or a scheme from the text; it may be a reaction, equation, concept, etc. or an imaginative illustration of a concept described in the manuscript, preferably in color. Spectra or other analytical data are not recommended. The image will be printed square with sides not larger than 2 inches $/ 5 \mathrm{~cm}$; the use of graphs and images consisting of several parts is therefore strongly discouraged.)) 